\title{
DRI from Recycled Iron Bearing Wastes for Lower Carbon in the Blast Furnace
}

\author{
Sung Hoon CHUNG, Ki Hyun KIM and II SOHN* \\ Department of Materials Science and Engineering, Yonsei University, 50 Yonsei-ro, Seodaemun-gu, Seoul, $120-749$ Korea. \\ (Received on September 1, 2014; accepted on October 24, 2014)
}

\begin{abstract}
Reduction of Fe-bearing FINEX process waste and carbon composite pellets from $1373 \mathrm{~K}$ to $1573 \mathrm{~K}$ to produce DRI (direct reduced iron) for use in the blast furnace was investigated using a modified thermogravimetric analyzer. Reduction from the initial $\mathrm{Fe}_{2} \mathrm{O}_{3}$ was not uniform throughout the composite pellet. Oxygen removal from the $\mathrm{Fe}_{2} \mathrm{O}_{3}$ rich composite pellets over $84 \%$ was only observed at $1573 \mathrm{~K}$. Lower temperatures resulted in significantly un-reduced $\mathrm{FeO}_{\mathrm{t}}$ due to the premature consumption of the carbon. A peripheral boundary of $\mathrm{FeO}_{\mathrm{t}} \cdot \mathrm{Al}_{2} \mathrm{O}_{3}$ and $2 \mathrm{FeO} \cdot \mathrm{SiO}_{2}$ phases surrounding the reducible $\mathrm{FeO}$ t was observed in some of the partially reduced cross-sectional SEM (scanning electron microscope) images that could hinder reduction. From the apparent activation energy, interfacial reaction seems to affect the kinetics of the Fe-bearing process waste composite pellets. Bursting of pre-dried composite pellets containing less than 2 mass\% moisture was simulated in a RHF hearth simulator. From direct observation of pellets charged between $1173 \mathrm{~K}$ to $1573 \mathrm{~K}$, medium-sized pellets between 9.4 to $12.4 \mathrm{~mm}$ diameter showed less bursting of the pellet, when charged below $1273 \mathrm{~K}$. In addition, modification of the physical strength of the hard bedrock formed from pellet bursting could be softened with additions of $\mathrm{SiO}_{2}$.
\end{abstract}

KEY WORDS: Fe-bearing process waste; RHF; blast furnace DRI; bursting; lower carbon in BF.

\section{Introduction}

Typical RHF (rotary hearth furnace) processes utilize iron ores with steaming or coking coals as the reductant in composite pellets or briquettes to produce DRI (direct reduced iron) or HBI (hot briquetted iron). But as higher priority is given to recycling and fully utilizing process wastes containing significant amounts of iron and carbon to optimize raw materials usage and lower production costs, integrated process wastes such as sludge, dust, and scale can be redirected back into the process stream after additional processing and reduction in the RHF. ${ }^{1-4)}$ Depending on the physical strength and chemical composition of the reduced pellet/briquette, the DRI/HBI can either be utilized either in the BF (blast furnace) or the steelmaking converters or the metallurgical furnaces. For an integrated steel plant producing 20 million tons per year, approximately 2 million tons of process wastes can be formed. The process waste starts from the initial raw materials handling stage in the sintering and cokemaking plants and continues to be generated until the finishing side of rolling.

Utilization of process wastes such as steelmaking dusts back into the sintering plant for the BF have been described by Makkonen et al.,5) where the economics and the physical properties of utilizing these secondary resources and the limitations involved with excess zinc, alkalies, and hydrocarbons were described. Koros ${ }^{6)}$ provided a review of the

\footnotetext{
* Corresponding author: E-mail: ilsohn@yonsei.ac.kr
}

DOI: http://dx.doi.org/10.2355/isijinternational.55.1157 overall recycling from process wastes including dust, scale, and sludge, where most of these materials in the past were recycled in the sinter plant while maintaining environmental compliance. Cold briquetting of dust and scrubber particulates showed possibilities of recycling back into the BF or the BOF (basic oxygen furnace), where smelting reduction occurs. ${ }^{7-9)}$ Others have shown the viability of utilizing new recycling technology such as the RHF after optimal agglomeration of the mixed secondary resources as a composite pellet or briquette to produce DRI with a metallization greater than $90 \%$, carbon content below 5 mass $\%$, and $\mathrm{Zn}$ rich baghouse dust for subsequent usage by the zinc producers. ${ }^{10-13)}$ Peng et al., ${ }^{14)}$ using an RHF simulator, studied the removal of $\mathrm{Zn}, \mathrm{Pb}$, and alkalis in cold bonded briquettes, where temperatures above $1573 \mathrm{~K}$ and $\mathrm{C} / \mathrm{O}$ molar ratio greater than unit ratio provided metallization of over $80 \%$ and $\mathrm{Zn}, \mathrm{Pb}$ contents to be low enough for BF utilization. Application of DRI with lower reduction degrees and comparatively higher sulfur into the BF produced from recycled waste material have been discussed in past literature. ${ }^{11,12)}$ However, incorporation of process wastes for DRI production has brought about significant issues that limit widespread utilization, even though utilizing DRI into BF decreases overall sinter feed input lowering the carbon requirements into the BF. Issues include pellet bursting or disintegration during rapid heating, excessive volatilization, increased fouling of heat exchangers and premature wear of stellite coated screw discharge devices, lower overall reduction degrees, and lower physical strength.

In this investigation, the reducibility of composite pellets 
with Fe-bearing dusts from the FINEX process and anthracite coal in a $\mathrm{Fe}_{2} \mathrm{O}_{3}$ to $\mathrm{C}$ ratio of 7 to 1 at temperatures between $1373 \mathrm{~K}$ to $1573 \mathrm{~K}$ was studied using a modified thermo-gravimetric analyzer. This ratio is typically less than the 4 to 1 ratio typically incorporated to obtain full reduction of composite pellets with excess carbon for improved melting rates, but was chosen to ascertain the amount of reduction possible with lower input carbon than conventional mixture ratios and overall lower carbon input into the blast furnace. Bursting and disintegration of rapidly heated pellets as a function of initial charging temperature and size of the pellet was also observed using the RHF hearth simulator. With bursting, a thick layer of unreduced pellet particles are compacted into a hard bedrock on the RHF hearth and subsequently act as an abrasive surface, which grinds the vanes of the screw discharge device. To lessen this impact and soften the bedrock for subsequent removal at the operating temperatures of the RHF, fluxes were added to control the liquidus temperature of the bedrock.

\section{Experimental Method and Procedure}

\subsection{Manufacturing of the Composite Pellet Using Pro- cess Wastes}

The major chemical compositions of the Fe-bearing dusts from the FINEX process are provided in Table 1. Fe bearing components have been analyzed using a wet analysis technique to distinguish metallic $\mathrm{Fe}, \mathrm{Fe}^{2+}$, and $\mathrm{Fe}^{3+}$ in the initial and final partially reduced composite pellet according to the standard analysis procedures stipulated in the standards for verification of the degree of final oxygen removal amount of composite pellets. ${ }^{15-17)}$ The majority of the initial $\mathrm{Fe}$ bearing components before reduction existed as $\mathrm{Fe}^{3+}$ in the $\mathrm{Fe}_{2} \mathrm{O}_{3}$ phase, as described in Table 1 . A LECO C/S combustion analyzer was used to measure the total carbon content after de-volatilization for unreduced and reduced pellets. Final content of carbon on all specimens were found to be less than 0.5 mass $\%$. As can be seen from the analysis, the average amount of input carbon was 10.3 mass \% with the $\mathrm{Fe}_{2} \mathrm{O}_{3}$ at approximately 77 mass \%. Anthracite coal was used for the carbon, but the volatile matter was typically volatilized before reduction. Less than 2 mass $\%$ of bentonite was used as a binder in the composite pellets and should not have a significant impact on the reducibility of the pellet. Using a disc pelletizer, pellets with an initial diameter from $14-17 \mathrm{~mm}$ and true densities of approximately $3.7 \mathrm{~g} / \mathrm{cm}^{3}$ was produced.

\subsection{RHF Hearth Simulator for Initial Rapid Heating of Composite Pellets}

A kanthal resistance box furnace was modified to simulate the RHF hearth conditions. The height of the box

Table 1. Average chemical composition of the Fe-bearing dust from the FINEX process and coal composite pellet utilized in the present study.

\begin{tabular}{ccccccc}
\hline \multicolumn{7}{c}{ Chemical Compositions (mass\%) } \\
\hline $\mathrm{Fe}_{2} \mathrm{O}_{3}$ & $\mathrm{CaO}$ & $\mathrm{SiO}_{2}$ & $\mathrm{MgO}$ & $\mathrm{Al}_{2} \mathrm{O}_{3}$ & $\begin{array}{c}\mathrm{C}_{\text {fixed }} \\
\text { (Initial) }\end{array}$ & $\begin{array}{c}\mathrm{C}_{\text {fixed }} \\
\text { (Final) }\end{array}$ \\
76.94 & $5.29 \pm 0.25$ & $4.00 \pm 0.19$ & $1.2 \pm 0.05$ & $2.27 \pm 0.15$ & 10.3 & $<0.5$ \\
\hline
\end{tabular}

furnace for initial feeding is approximately $1 / 3$ of the drop height observed in the actual RHF process. The temperature inside the box furnace was controlled using a PID (proportional integral derivative) controller with a $\pm 3 \mathrm{~K}$ deviation from target temperature. HP Ar (99.999\%) of 2 slpm was passed into the furnace to control the oxygen partial pressure to a maximum of $10^{-8} \mathrm{~atm}$. Prior to direct insertion of the green pellet, some pellets were typically pre-dried to approximately $473 \mathrm{~K}\left(200^{\circ} \mathrm{C}\right)$ to remove the surface adsorbed moisture comparable to the RHF process. Insertion holes and viewport holes were machined at the top and front of the box furnace, as illustrated in Fig. 1(a). $\mathrm{Al}_{2} \mathrm{O}_{3}$ refractory boards were manually constructed to encase particulate bursting materials, protection of the heating elements, and also to ensure better heat uniformity in the RHF hearth simulator. A high temperature lens filter (VF-49MPAM/CSYH; Sony, Tokyo, Japan) was used for the high speed digital camera for in-situ observation of the pellet characteristics.

\subsection{Reduction Tests Using a Modified Microbalance}

Composite pellets weighing approximately between 6-9 g were placed within a Pt- $10 \% \mathrm{Rh}$ wire mesh into an isolated vertical $\mathrm{SiC}$ resistance furnace. The mesh was connected with the same material wire onto the bottom of the load cell of the microbalance, as shown in Fig. 1(b). The pellets were initially above the hot zone of the furnace to ensure reaction of the pellets does not occur. As the hot zone of the furnace reach the target temperature of $1373 \mathrm{~K}$ to $1573 \mathrm{~K}$, the pellet and the microbalance stage is lowered by a motorized drive assembly towards the hot zone. The pellet starts to react after $120 \mathrm{~s}$ as the pellet is heated and another $180 \mathrm{~s}$ is required for achieving stable readings from the microbalance. The amount of mass change during insertion into the hot zone and stabilization was not significant and neglected in the present study. Data was collected at $1 \mathrm{~Hz}$. Within the experimental temperature of $1373 \mathrm{~K}$ to $1473 \mathrm{~K}$, the composite pellets existed in the solid form and was absent of any liquid phases according to the observation of partially and fully reduced cross-sectional micrographs and also during the RHF simulation tests. However, at $1573 \mathrm{~K}$, partial melting and softening of the composite pellet could be observed, as illustrated in a subsequent section. At $1573 \mathrm{~K}$ after partial reduction occurs from $\mathrm{Fe}_{2} \mathrm{O}_{3}$ to $\mathrm{FeO}$, the target experimental temperature is near the melting temperature of wustite $(\mathrm{FeO})$ and the existence of $\mathrm{SiO}_{2}$ in the composite pellet may also form the low temperature phase fayalite $\left(2 \mathrm{FeO} \cdot \mathrm{SiO}_{2}\right)$, as suggested by Wright et al. ${ }^{18)}$ The oxygen is removed only from the $\mathrm{Fe}_{2} \mathrm{O}_{3}$ in the composite pellet and other oxides are thermodynamically un-favorable for reduction in the present temperature range. Considering the reactions taking place for a self-reducing composite pellet, as described in previous literature, ${ }^{19-21)}$ the overall reaction can be assumed to follow reaction (1). The percent of oxygen removed could be obtained from Eq. (2). ${ }^{19)}$

$$
\mathrm{Fe}_{2} \mathrm{O}_{3}(s)+3 \mathrm{C}(s)=2 \mathrm{Fe}(s)+3 \mathrm{CO}(g)
$$

Oxygen removed $(\%)=$

$\frac{\Delta w}{w_{\text {Initial }} \times(100-\text { unreducible oxides } \%)} \times \frac{M W_{\mathrm{Fe}_{2} \mathrm{O}_{3}}+3 M W_{\mathrm{C}}}{3 M W_{\mathrm{CO}}}$



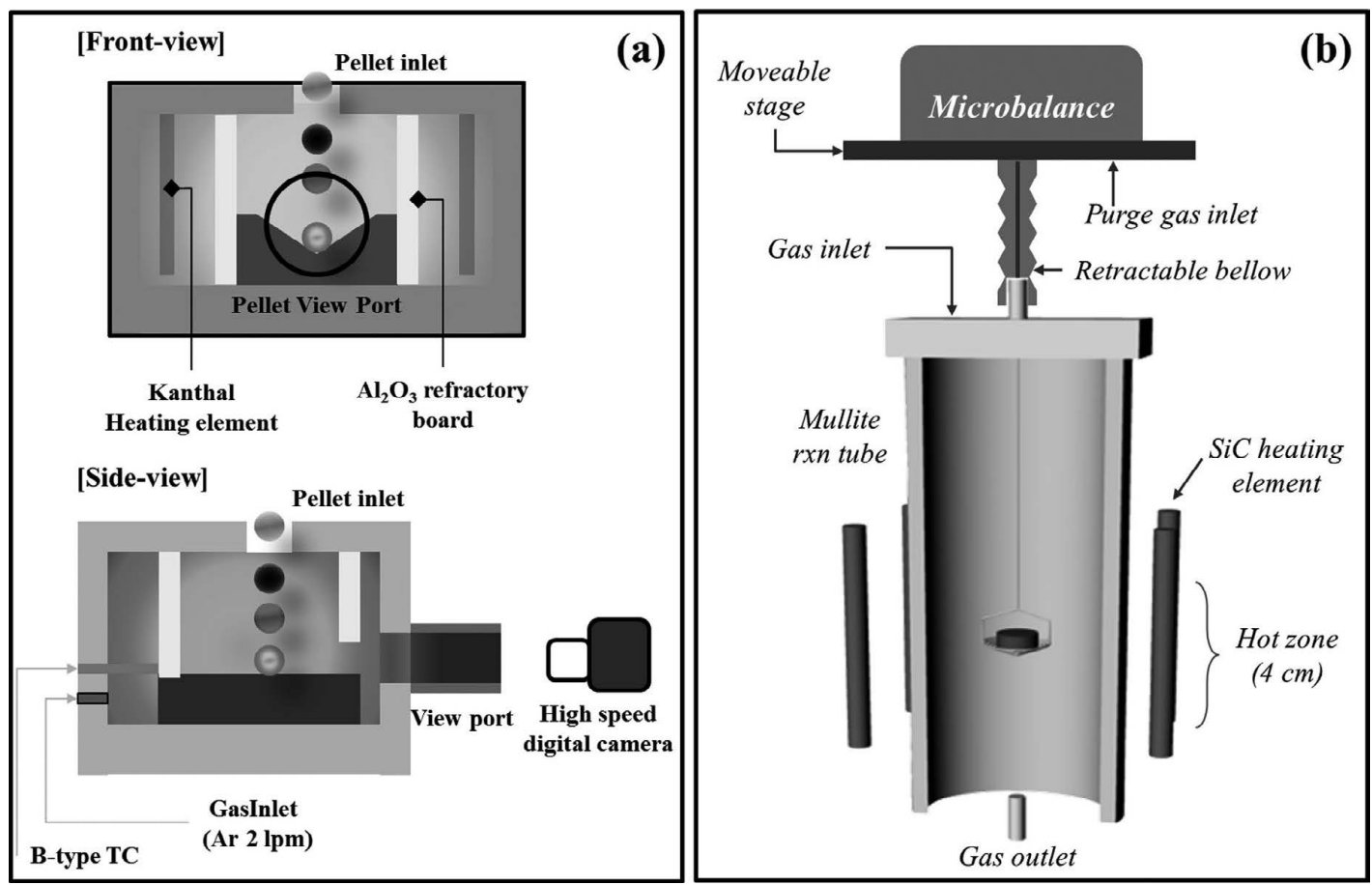

Fig. 1. Schematic of the modified (a) box furnace for bursting tests simulating the RHF hearth and (b) SiC vertical resistance furnace with $\mathrm{Pt}-10 \% \mathrm{Rh}$ wire mesh holding the composite pellet connected to the microbalance.

where, $\Delta w$ is the weight loss of the sample, $w_{\text {Initial }}$ is the initial weight of the composite pellet, and $M W_{i}$ is the molecular weight of the species ' $i$ '. Within the composite pellets, unreducible oxides such as $\mathrm{CaO}, \mathrm{SiO}_{2}, \mathrm{MgO}$, and $\mathrm{Al}_{2} \mathrm{O}_{3}$ can exist, which is provided in Table 1.

Reaction (1) addresses the overall reaction of $\mathrm{Fe}_{2} \mathrm{O}_{3}$ to $\mathrm{Fe}$ with carbon, but does not address the stepwise reduction of $\mathrm{Fe}_{2} \mathrm{O}_{3}$ to $\mathrm{Fe}_{3} \mathrm{O}_{4}$ to $\mathrm{FeO}$ to $\mathrm{Fe}$, as suggested by many past publications. ${ }^{22-25)}$ Furthermore, while the direct reduction of carbon with $\mathrm{Fe}_{2} \mathrm{O}_{3}$ initiates the removal of oxygen in the composite pellets, it is well-known that the gaseous intermediate indirect reduction with $\mathrm{CO}$ and $\mathrm{CO}_{2}$ is the dominant reaction occurring within the composite pellets. And as pointed out by Rao, ${ }^{22)}$ Srinivisan and Lahiri, ${ }^{23)}$ Abraham and Ghosh, ${ }^{24)}$ and Fruehan, ${ }^{25)}$ the carbon gasification (Boudouard reaction) plays an important role in determining the overall rate, as expressed in reaction (3). This results in the production of $\mathrm{CO}$ gases within the pellet to further stimulate reduction by reaction (4)

$$
\begin{array}{r}
\mathrm{C}(s)+\mathrm{CO}_{2}(g)=2 \mathrm{CO}(g) \\
\mathrm{Fe}_{2} \mathrm{O}_{3}(s)+3 \mathrm{CO}(g)=2 \mathrm{Fe}(s)+3 \mathrm{CO}_{2}(g)
\end{array}
$$

The overall direct and indirect reactions can be expressed by reaction (1) and (4), respectively and depending on the $\mathrm{CO}$ and $\mathrm{CO}_{2}$ concentrations, the amount of carbon needed to reduce 1 mole of $\mathrm{Fe}_{2} \mathrm{O}_{3}$ can vary between 1.5 to 3 moles. It should be mentioned that the reduction does not occur uniformly throughout the entire pellet and a mixture of $\mathrm{Fe}_{2} \mathrm{O}_{3}$ and $\mathrm{FeO}_{\mathrm{t}}$ phases co-existed during the reduction process, which was visually verified by morphological examination provided in a subsequent section.

\section{Results and Discussion}

\subsection{Reduction Behavior of Self-reducing Fe-bearing Waste Composite Pellets}

Reduction of pre-dried and devolatilized Fe-bearing FINEX process wastes with anthracite coal is shown in Fig. 2(a) at temperatures from $1373 \mathrm{~K}$ to $1573 \mathrm{~K}$. The initial reduction rate from the linear slope after $10 \%$ oxygen removal from the composite pellet provided in Fig. 2(b) showed the rate to significantly increase with temperature. A final reduction of over $84 \%$ is achieved for the pellets reduced at $1573 \mathrm{~K}$. Only $63 \%$ of oxygen is removed for pellets reduced at $1373 \mathrm{~K}$. Beyond $2000 \mathrm{~s}$ of reduction at the target temperature, additional oxygen removal in the sample was not observed. Samples taken after $2000 \mathrm{~s}$ were removed from the hot zone of the furnace and quenched with Ar and analyzed for final carbon and oxygen, which is compared with the initial carbon and oxygen to verify the final oxygen removal percent. Final carbon content in the partially reduced composite pellets were found to be less than $0.5 \mathrm{mass} \%$. This was likely the premature consumption of carbon before full reduction of the samples could occur. Although ideally the production of $\mathrm{CO}$ and subsequently the reaction of $\mathrm{FeO}_{\mathrm{t}}$ within the pellet is expected to occur, the $\mathrm{CO}$ gas may not be retained within the pellet long enough or may not directly contact the $\mathrm{FeO}_{\mathrm{t}}$ for reduction to take place resulting in unreacted $\mathrm{CO}$ evolution that escapes the pellet reaction boundary towards the bulk gas, which is then swept away by the flowing Ar carrier gas. The premature consumption of carbon is likely reaction (3) occurring without reaction (4), which lowers the carbon content for reduction to take place. At lower temperatures this is more pronounced since the kinetics of the reduction is slower, but the retention time of $\mathrm{CO}$ within the pellet is not long and effective reaction with the $\mathrm{FeO}_{\mathrm{t}}$ in the composite pel- 

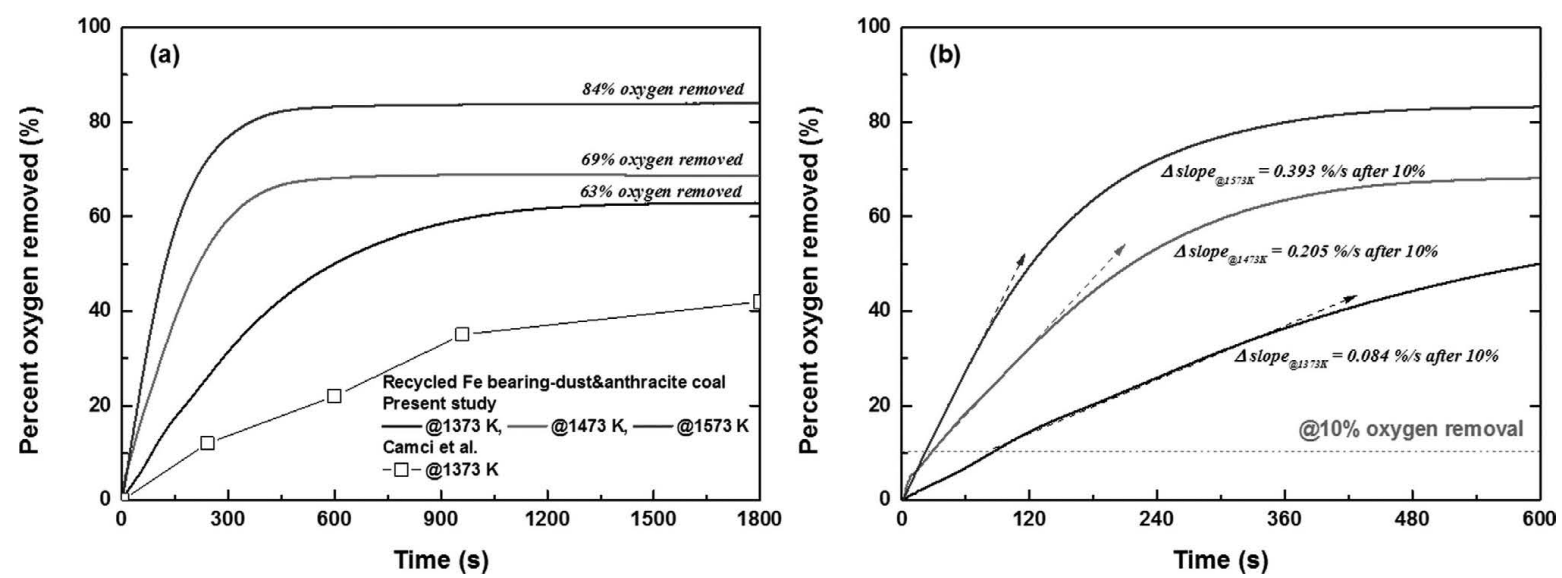

Fig. 2. (a) Percent oxygen removed of self-reducing composite pellets using Fe-bearing process wastes and anthracite coals at various temperatures and (b) the initial reduction rate after $10 \%$ oxygen removal.
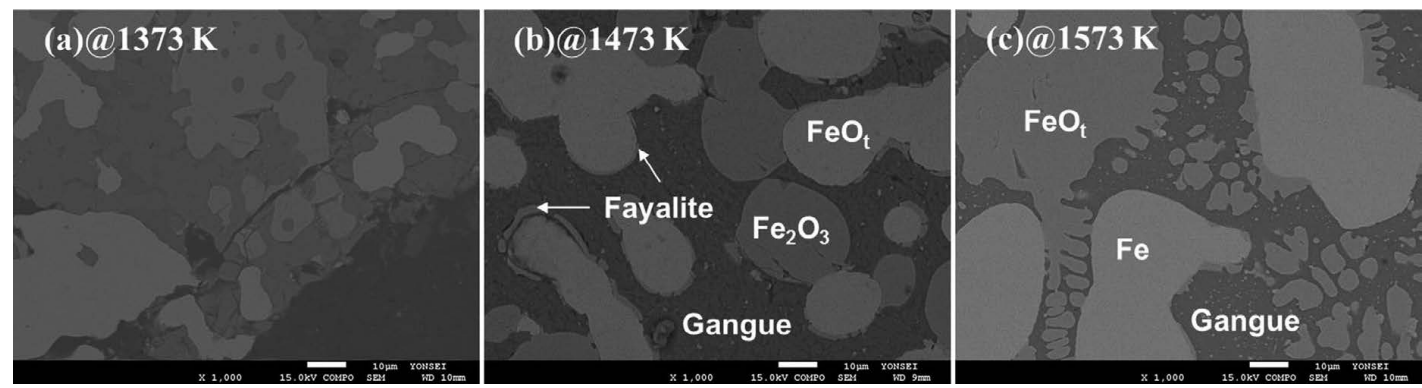

Fig. 3. Morphological observation using the back-scattered SEM of samples reduced for $2000 \mathrm{~s}$ and as-quenched under a flow of Ar gas.

let before diffusion out of the pellet is not fast enough to achieve a high reduction percent, as observed in Fig. 2(a).

Thus, while the reduction maybe initiated by the direct reduction of $\mathrm{Fe}_{2} \mathrm{O}_{3}$ with $\mathrm{C}$, the indirect reduction by $\mathrm{CO}$ produced through the $\mathrm{C}$ and $\mathrm{CO}_{2}$ endothermic reaction (3) is limited after the consumption of carbon is completed. Similar to the work of Camci et al., ${ }^{2)}$ where mixtures of mill scale, sludge and dust were utilized, full reduction of the composite pellets are not obtained unless excess carbon is provided for complete reduction at lower temperatures of less than $1473 \mathrm{~K}$.

Backscattered SEM (scanning electron microscopy) images of reduced composite pellets after $2000 \mathrm{~s}$ asquenched under an Ar gas flow are shown in Fig. 3. Partially reduced $\mathrm{FeO}_{\mathrm{t}}$ and metal $\mathrm{Fe}$ co-exist within the specimen. Some of the specimens, in particular show a peripheral boundary of $\mathrm{FeO}_{\mathrm{t}}$-compounds encasing reduced iron oxides, which may inhibit further removal of oxygen from the Fe-bearing oxide. Some of the constituent oxides within the Fe-bearing oxide such as $\mathrm{MgO}, \mathrm{Al}_{2} \mathrm{O}_{3}$, and $\mathrm{SiO}_{2}$ may form compounds such as $2 \mathrm{FeO} \cdot \mathrm{SiO}_{2}$ and solid solutions of $\mathrm{FeO}_{\mathrm{t}} \cdot \mathrm{Al}_{2} \mathrm{O}_{3}$ at the temperature of interest lowering the activity of the Fe-bearing oxides that can interfere with the removal of oxygen.

From the temperature dependency of the initial rates expressed in Eq. (5), the slope of the reciprocal of temperature and the natural logarithm of the apparent rates resulted in an apparent activation energy of approximately $135 \mathrm{~kJ} / \mathrm{mol}$. ' $k$ ' is the apparent rate constant $(\% / \mathrm{s})$, ' $\Delta E$ ' is the apparent activation energy $(\mathrm{J} / \mathrm{mol})$, ' $\mathrm{R}$ ' is the ideal gas constant $(8.314 \mathrm{~J} / \mathrm{K} \cdot \mathrm{mol})$, and ' $T$ ' is absolute temperature $(\mathrm{K})$. The slope is taken from the linear region beyond $10 \%$ of oxygen removed, which is expected to be the region where the intermediate gaseous reactions are dominant within the composite pellets and also have relatively extended linear regions up to approximately $30 \%$ oxygen removed. This activation energy is somewhat higher than the mass transfer controlled reactions indicated by others, ${ }^{19,26-28)}$ where the gaseous diffusion through the reduced porous Fe layer were estimated to be between $8-26 \mathrm{~kJ} / \mathrm{mol}^{19,26)}$ and the bulk mass transfer of $\mathrm{CO}$ to the reaction interface of $\mathrm{FeO}$ to be between 64-74 kJ/mol. ${ }^{27,28)}$ However, the estimated apparent activation energy of the present study seems to fall within the range of 116 to $127 \mathrm{~kJ} / \mathrm{mol},{ }^{29,30)}$ where chemical kinetics of $\mathrm{CO}$ gas with $\mathrm{FeO}$ is rate controlling. Moreover, higher sensitivity of the overall oxygen removal percent and the slope with temperature also suggest chemical kinetics at the reaction interface to be an important factor determining the rate.

$$
\ln k=\ln k_{0}-\frac{\Delta E}{R T}
$$

\subsection{Effect of Initial Charging Temperature on the Bursting of Various Sized Composite Pellets}

The green pellets are charged into the RHF at initially high temperatures, which rapidly heats the composite green pellets. Depending on the initial charging temperature, the pellets have been found to show disintegration or bursting characteristics. Composite pellets that have not been predried may contain water moisture of more than 2 mass $\%$ 

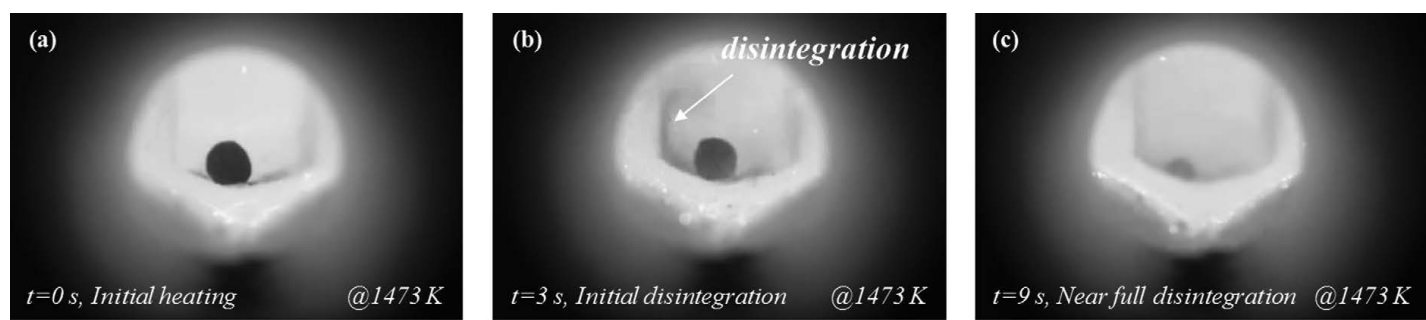

Fig. 4. Digital image of rapid heating of un-dried green composite pellets and subsequent disintegration at $1473 \mathrm{~K}$ with moisture content above 2 mass $\%$.

and result in rapid disintegration of the pellet in less than $10 \mathrm{~s}$, as shown in Fig. 4 for pellets heated at $1473 \mathrm{~K}$. Similar disintegration of the pellet was observed for temperatures above $1273 \mathrm{~K}$. Thus, pellets with significant absorbed moisture is rapidly heated and before conduction of heat towards the core can take place, most of the surface moisture exposed to heat is vaporized and the pellet is disintegrated topo-chemically from the outside towards the core layer by layer. The pellets used for the present study in the thermo-gravimetric analysis and RHF process contained less than 2 mass $\%$ moisture.

For pre-dried rapid heating experiments with absorbed moisture content below 2 mass\%, three size groups (small, medium, and large) with comparable densities were chosen for the rapid heating at various target temperatures. Small diameter sized groups were between 6.5 to $9.4 \mathrm{~mm}$, medium diameter sized groups were between 9.4 to $12.4 \mathrm{~mm}$, and large diameter sized groups were between 12.4 to $15 \mathrm{~mm}$. Target temperatures ranged from $1173 \mathrm{~K}\left(900^{\circ} \mathrm{C}\right)$ to $1573 \mathrm{~K}$ $\left(1300^{\circ} \mathrm{C}\right)$ at $100 \mathrm{~K}$ intervals. Small sized pellets showed pellet bursting at the entire range of heating temperatures with some pieces of DRI that were found to be above $4.75 \mathrm{~mm}$. Unlike disintegration of pellets, pellet bursting entails conduction of heat towards the core and subsequent pressure build-up within the pellet resulting in the explosion of a pellet from within into several pieces of composite materials. For the medium sized group pellets between 9.4 to $12.4 \mathrm{~mm}$ diameter (medium size group), initial charging of pre-dried green pellets at $1573 \mathrm{~K}\left(1300^{\circ} \mathrm{C}\right)$ resulted in pellet bursting. Large sized group pellets between 12.4 to $15.0 \mathrm{~mm}$ showed bursting up to $1273 \mathrm{~K}\left(1000^{\circ} \mathrm{C}\right)$ and below $1273 \mathrm{~K}\left(1000^{\circ} \mathrm{C}\right)$ the majority of the pellet did burst, but some pellets were larger than $4.75 \mathrm{~mm}$. Sinter size of greater than $4.75 \mathrm{~mm}$ diameter is utilized for blast furnace sinter feeds to maintain optimal gas flows and thus DRI pellets above this critical diameter are considered viable for the BF feed materials. ${ }^{3)}$ From the rapid heating tests, the optimal size and initial charging temperature for the RHF hearth was found to be the medium sized pellet at a charging temperature of less than $1273 \mathrm{~K}\left(1000^{\circ} \mathrm{C}\right)$, as shown in Fig. 5. The yield of DRI was obtained by selecting those samples larger than $4.75 \mathrm{~mm}$ after charging and comparing with the total number of rapid heating trials at the specified target temperature for the particular pellet diameter. Typical series of charging experiments exceeds more than ten pellets per temperature per pellet diameter. According to past work regarding rapid heating of $14 \mathrm{~mm}$ diameter composite pellets by Seaton et al., ${ }^{31)}$ there exists thermal gradients between the core and surface, which require as much as $30 \mathrm{~min}$ for thermal equilibrium to be achieved. At tem-
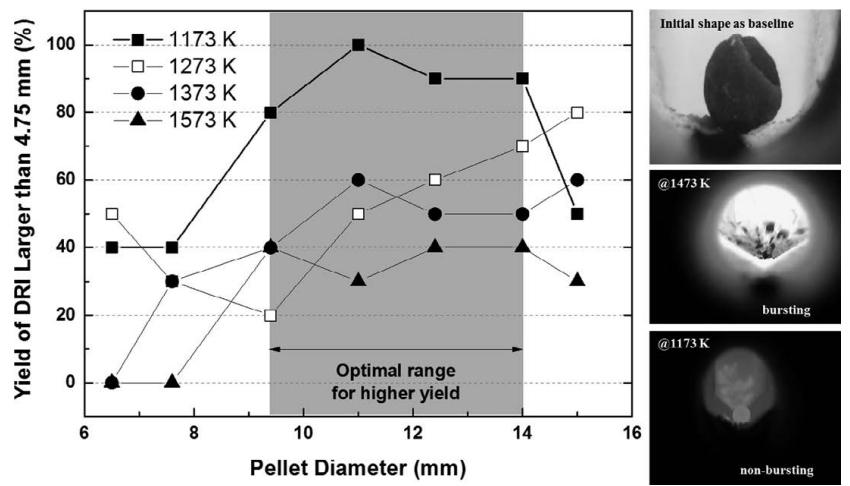

Fig. 5. Pre-dried pellet bursting at various insertion temperatures between $1173 \mathrm{~K}$ to $1573 \mathrm{~K}$ within the RHF hearth simulator and the digital image of the bursting phenomena.

peratures of $1473 \mathrm{~K}\left(1200^{\circ} \mathrm{C}\right)$, the difference between the core and surface can exceed more than 100 degrees, but at temperatures of $1273 \mathrm{~K}\left(1000^{\circ} \mathrm{C}\right)$, the temperature difference seems to be significantly less than 20 degrees. It would seem that the volatiles existing near the surface can escape without much resistance due to the rapid heat transfer, but heat transfer towards the core can be delayed, as observed by Seaton $e t a l .{ }^{31)}$ During this heat conduction towards the core, the devolatilized exterior is reduced and sintering may occur, which decrease the mean free path of the gases to escape. As the core temperature reaches significant temperatures for devolatilization and subsequent carbon gasification is initiated, gas evolution is accelerated and builds-up within the core of the pellet, but cannot escape fast enough and thus reaches a critical internal pressure resulting in bursting. For large pellets, the temperature gradients between the core and the surface maybe greater that is likely to promote bursting of the pellets. For small pellets, the temperature gradients between the core and surface may not be as significant as the larger pellets, but the critical pressure for bursting is likely less than the larger pellets and even a small amount of breakage within the pellet will fall below the $4.75 \mathrm{~mm}$ diameter limit for use in the BF. Thus, the medium sized pellets have shown the optimal resistance to bursting depending on the initial charging temperature.

In order for RHF operations to effectively produce DRI pellets with minimal losses to the bursting phenomena, composite green pellets should be sufficiently dried to less than 1 mass \% water content or charge the green pellets at temperatures lower than $1073 \mathrm{~K}\left(800^{\circ} \mathrm{C}\right) .^{3)}$ But lower temperatures result in slower kinetics of reduction and subsequently may result in lower reduction degrees if the rotation speed of the hearth is kept constant. Thus, maximizing hearth temperature with minimum bursting is required in the RHF. 

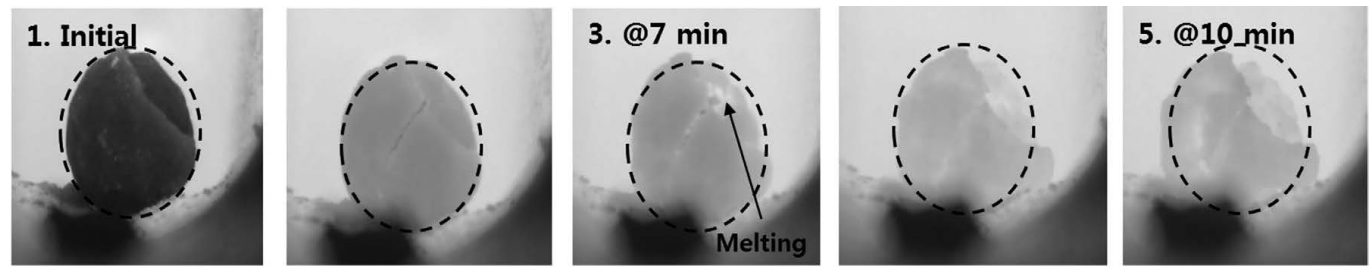

time $=0 \mathrm{~s}$
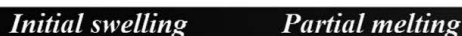

Overall softening

time $=600 \mathrm{~s}$

Fig. 6. Partial melting and softening of reduced composite pellets held at $1573 \mathrm{~K}$ for 10 minutes. The dashed boundary line provided as a guide.
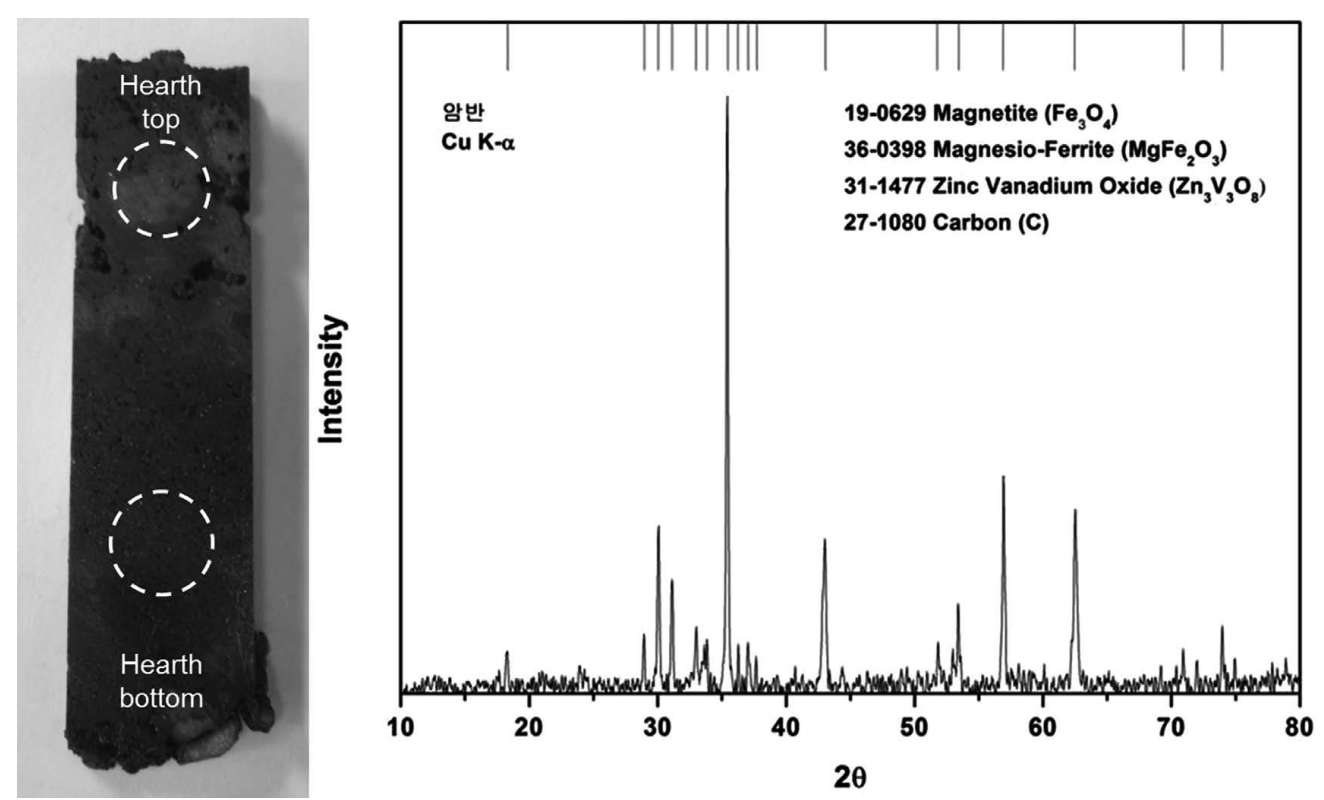

Fig. 7. Digital image of the rockbed formation due to bursting of the Fe-bearing carbon composite pellets and XRD analysis.

However, heating to excessive temperature can create additional problems, which was not apparent at lower temperatures. Heating of the pellet at $1573 \mathrm{~K}\left(1300^{\circ} \mathrm{C}\right)$ and holding for prolonged periods can result in partial melting and softening of the pellet as shown in Fig. 6, which may result in difficulty of the DRI product to be removed from the hearth as it is pressed into the bed instead of being guided out through the screw discharge exit hole. It should also be noted that there is an initial expansion of the pellet, which is evident from the change in the proximity of the pellets outer layer and the dashed guidelines provided in the digital image. This initial swelling has been studied in detail by many ${ }^{32-36)}$ and regarded as a result of iron whisker growth during reduction, but is likely also affected by the product gases formed during the reduction and subsequent pressure build-up. After 7 minutes, the pellet begins to soften and melt resulting in significant deformation after 10 minutes. Thus, RHF temperatures of $1573 \mathrm{~K}\left(1300^{\circ} \mathrm{C}\right)$ and higher in the reduction zone of the furnace should be less than 7 minutes of the total reaction time to lower the possibility of significant softening and melting. Higher operating temperatures for the RHF beyond $1573 \mathrm{~K}$ are possible and typical of the ITMk3 technology, but the contents of the ITMk3 is not the focus of this work. It can be speculated that the partial melting phenomena after extended periods is likely the result of iron carburization and the subsequent lowering of the melting temperature as defined by the $\mathrm{Fe}-\mathrm{C}$ phase diagram. DRI containing approximately 2.5 mass $\%$ $\mathrm{C}$ has a melting temperature of about $1623 \mathrm{~K}\left(1350^{\circ} \mathrm{C}\right)$ according to ThermoCalc, which is close to the maximum operating temperatures of the RHF utilizing recycled process wastes.

\subsection{Bedrock Formation and Softening}

Figure 7 shows the digital image of a bedrock sample taken from the hearth of an operational RHF. Below the bedrock $\mathrm{MgO}$ chips are placed on the initial surface of the hearth during start-up to minimize materials sticking directly on the permanent refractory of the hearth. Above the $\mathrm{MgO}$ chips, the raw materials of the bursted pellets are densely packed and the major chemical composition from the SEM-EDS and XRD analysis was shown to be high in $\mathrm{Fe}, \mathrm{Mg}$, and $\mathrm{C}$ with the characteristic peaks indicating a magnetite, magnesio-ferrite and carbon with small amounts of zinc vanadium oxide. Magnetite and magnesio-ferrite are relatively a high temperature phase and can abrasively damage the screw discharge device of the RHF.

Considering the $\left(\mathrm{Fe}_{2} \mathrm{O}_{3}-\mathrm{FeO}\right)-\mathrm{MgO}-\mathrm{SiO}_{2}$ pseudo-ternary phase diagram according to slag atlas in Fig. 8, the high temperature phase of the iron oxide and magnesio-ferrite can be directed towards the lower temperature phase with the addition of $\mathrm{SiO}_{2}$. For the binary $\mathrm{FeO}-\mathrm{MgO}$ phase region, 


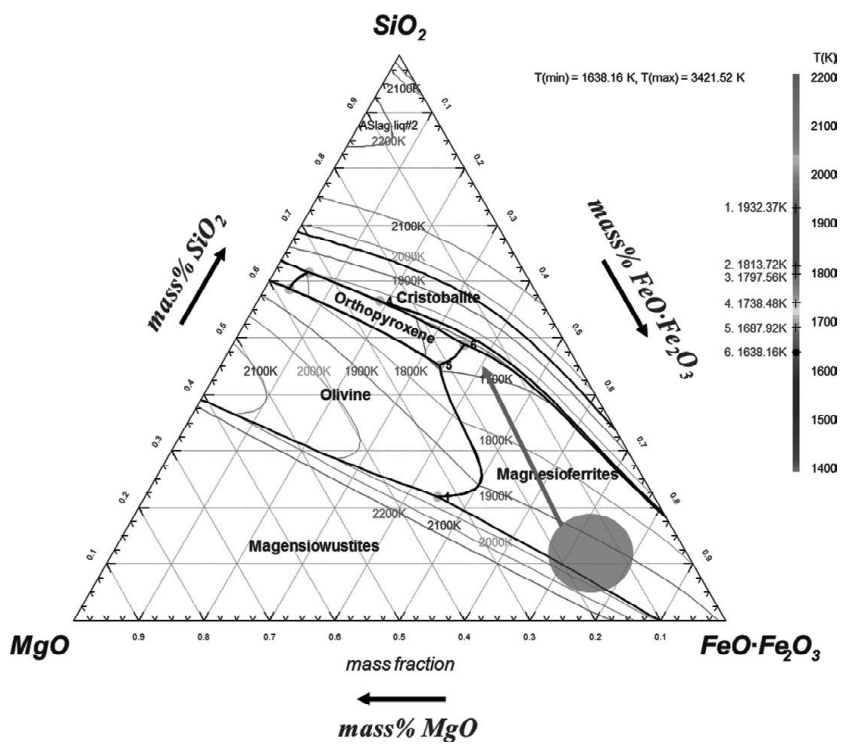

Fig. 8. $\left(\mathrm{Fe}_{2} \mathrm{O}_{3}-\mathrm{FeO}\right)-\mathrm{MgO}-\mathrm{SiO}_{2}$ psuedo-ternary phase diagram from slag atlas. Note the decrease in the liquidus temperature with $\mathrm{SiO}_{2}$ additions from the $\mathrm{FeO}_{\mathrm{t}}$ rich region towards the $\mathrm{SiO}_{2}$ rich region.

(a) Bedrock@1350॰ C

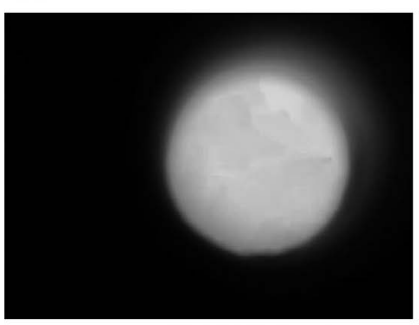

(b) Bedrock\&SiO ${ }_{2} @ 1350^{\circ} \mathrm{C}$
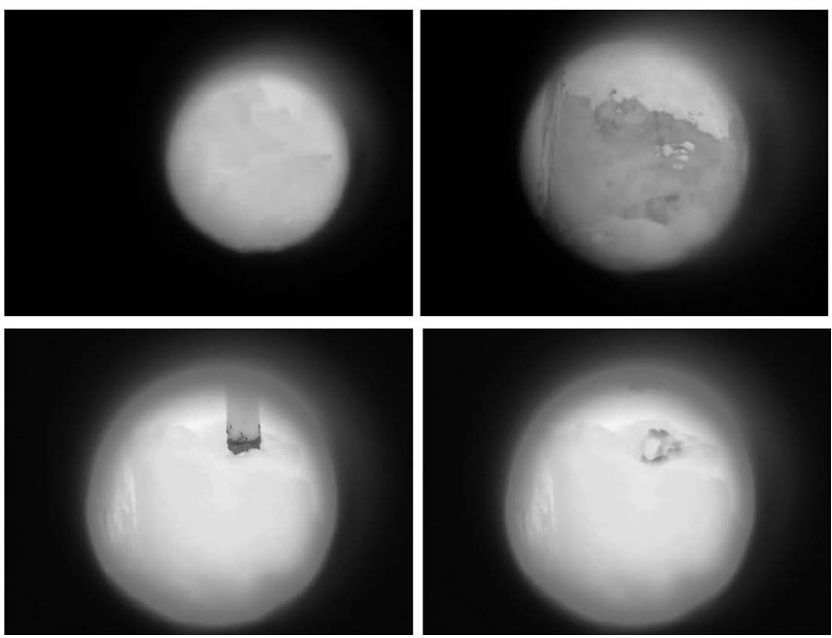

Fig. 9. Bedrock softening@ $1350^{\circ} \mathrm{C}$ through addition of $\mathrm{SiO}_{2}$ fluxes on top of sample.

the liquidus temperature of the phase is relatively high. With additions of $\mathrm{SiO}_{2}$, the composition is pushed towards the $\mathrm{SiO}_{2}$ rich region resulting in lower temperatures. Hearth temperatures of $1623 \mathrm{~K}\left(1350^{\circ} \mathrm{C}\right)$, which is the maximum temperature of the RHF process for the present applications, was simulated with the bedrock. Approximately $5 \mathrm{~g}$ of $\mathrm{SiO}_{2}$ were sprinkled atop the bedrock and the reaction was observed in-situ using the high speed digital camera installed with the bright image filter. Figure 9 provides the digital images of the reaction and the physical hardness of the bedrock after $\mathrm{SiO}_{2}$ fluxing was determined from direct contact with a high density alumina lance. At $1623 \mathrm{~K}$ $\left(1350^{\circ} \mathrm{C}\right)$, the $\mathrm{SiO}_{2}$ was found to react with the $\mathrm{FeO}_{\mathrm{x}}$ to form fayalite, which is comparatively soft at the set temperature. The fayalite also adheres well with the alumina surface, which suggests removal with the screw discharge device may become significantly easier with $\mathrm{SiO}_{2}$ additions. At $1573 \mathrm{~K}\left(1300^{\circ} \mathrm{C}\right)$, the softening of the bedrock could

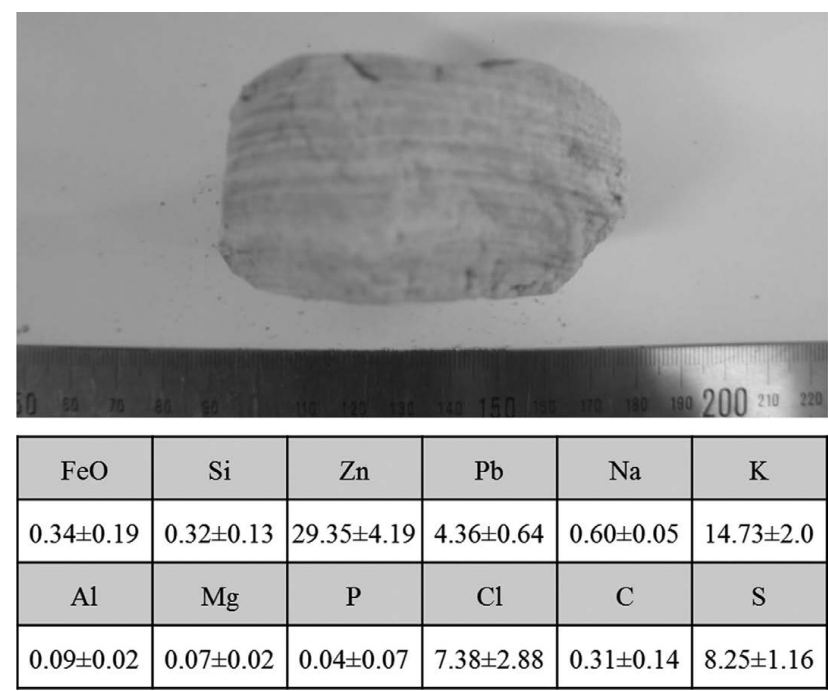

Fig. 10. Digital image of retrieved material adhered on the recuperator exchange tubes and its average elemental chemical composition.

not be observed and suggested removal of the bedrock after fluxing needs at least the temperature to be higher than $1623 \mathrm{~K}\left(1350^{\circ} \mathrm{C}\right)$ for possible removal.

\subsection{Adhered Material on the Heat Exchange Tube of the Recuperator}

To assist in the economic feasibility of the RHF process for waste recycling, process off-gas heat can be utilized for preheating the raw materials and combustion gases for the RHF. This exchange of process off-gas can be seriously hindered, when exogenous materials foul the heat exchanger tubes of the recuperator. Figure $\mathbf{1 0}$ is a digital image of the adhered material taken during the maintenance shutdown of the RHF process. Elemental chemical analysis of the adhered material using ICP, $\mathrm{Cl}$ analysis, and $\mathrm{C} / \mathrm{S}$ analysis showed the major constituents to be $\mathrm{Zn}, \mathrm{K}, \mathrm{Fe}$, and $\mathrm{Cl}$. The XRD analysis also revealed the major phases of the elemental constituents to be a $\mathrm{ZnCl}_{2}$ and $\mathrm{KCl}_{2}$ compound with the iron in the $\mathrm{FeO}$ and $\mathrm{Fe}_{3} \mathrm{O}_{4}$ form. It would seem that the major raw materials that provide these adhering materials making the recuperator operation difficult are sources, where $\mathrm{Zn}$ and $\mathrm{K}$ are abundant. Thus, removing this raw material from the mixing recipe was found to significantly increase the operational availability of the recuperator.

\section{Conclusions}

In this study, the reduction of self-reducing Fe-bearing process waste and carbon composite pellets from $1373 \mathrm{~K}$ to $1573 \mathrm{~K}$ was studied. Final oxygen removal of over $84 \%$ can be achieved for samples reacted at $1573 \mathrm{~K}$, but less than $70 \%$ oxygen removal was observed at lower temperatures. Indirect reduction by $\mathrm{CO}$ gases through the gasification of $\mathrm{C}$ is effective at higher temperatures and is comparatively slower at temperatures below $1573 \mathrm{~K}$. A peripheral boundary of $\mathrm{FeO}_{\mathrm{t}}$ with $\mathrm{Al}_{2} \mathrm{O}_{3}$ and $\mathrm{SiO}_{2}$ compounds were observed for pellets reduced at lower temperatures, which could have hindered further reduction of the composite pellets. The apparent activation energy was approximately $135 \mathrm{~kJ} / \mathrm{mol}$, which suggested interfacial reaction to play an important 
role in the kinetics of the reaction.

For composite pellets charged into the RHF hearth at temperatures between $1173 \mathrm{~K}$ to $1573 \mathrm{~K}$, medium-sized groups between 9.4 to $12.4 \mathrm{~mm}$ diameter showed less bursting of the pellet, when charged below $1273 \mathrm{~K}$. Using simple fundamental thermodynamic principles and the phase diagram, the hard bedrock formed from the composite pellet bursting could be softened with additions of $\mathrm{SiO}_{2}$, which was visually verified in the RHF hearth simulator. Adhered materials of the recuperator warranted waste by-products to be low in $\mathrm{Zn}, \mathrm{K}$, and $\mathrm{Cl}$ for optimal heat recovery in the RHF

\section{Acknowledgements}

This study was partially supported by the Brain Korea 21 PLUS (BK21 PLUS) Project at the Division of the EcoHumantronics Information Materials and the Ministry of Trade, Industry, and Energy project No.2013-11-2008.

\section{REFERENCES}

1) N. L. Kotraba and N. E. Bottinelli: Proc. Int. Symp. Extr. Process Treat. Minimization Wastes, Miner. Met. Mater. Soc., Warrendale, PA, (1994), 521.

2) L. Camci, S. Aydin and C. Arslan: Turkish J. Eng. Env. Sci., 26 (2002), 37.

3) Y. S. Lee, D. W. Ri, S. H. Yi and I. Sohn: ISIJ Int., 52 (2012), 1454

4) R. H. Hanewald and D. E. Dombrowski: Iron Steel Eng., 62 (1985), 62.

5) H. T. Makkonen, J. Heino, L. Laitila, A. Hiltunen, E. Pöyliö and J. Härkki: Resour. Conserv. Recy., 35 (2002), 77.

6) P. J. Koros: Metall. Mater. Trans. B, 34 (2003), 769.

7) M. P. Landow, M. I. Crawford and M. Martinez: 56th Ironmaking Conf. Proc., ISS, Warrendale, PA, (1997), 95.

8) R. Baiajee, P. E. Callaway and L. M. Keilman: Steelmaking Conf. Proc., ISS, Warrendale, PA, (1995), 51.

9) C. L. Molloseau and R. J. Fruehan: Iron Steelmaker, 27 (2000), 47.
10) J. M. McClelland and G. E. Metius: JOM, 55 (2003), 30.

11) J. M. McClelland: 61 st Ironmaking Conf. Proc., ISS, Warrendale, PA, (2002), 667.

12) P. E. Duarte and J. Becerra: Stahl Eisen, 131 (2011), S85.

13) T. Ibaraki and H. Oda: Rev. Metall. CIT., 99 (2002), 809.

14) C. Peng, F. Zhang, H. Li and Z. Guo: ISIJ Int., 49 (2009), 1874.

15) Korea Industrial Standards Commission: Determination of Metallic Iron through the Bromine-methanol Titration Method, KS-EISO-5416, KISC, Seoul, Korea, (2006).

16) Korea Industrial Standards Commission: Determination of Acidsoluble Iron (II) Content Titration method, KS-E-ISO-9035, KISC, Seoul, Korea, (1989).

17) Korea Industrial Standards Commission: Determination of the Total Iron Content Using the Titration Method after Tin (II) Chloride Reduction, KS-E-ISO-2597-1, KISC, Seoul, Korea, (2006).

18) J. K. Wright, Jr., M. Shelef and R. A. Anderson: Chemistry and Physics of Carbon, Marcel Dekker, New York, (1968), 287.

19) S. M. Jung and S. H. Yi: Steel Res. Int., 84 (2013), 908.

20) Y. Ueki, R. Mii, K. Ohno, T. Maeda, K. Nishioka and M. Shimizu: ISIJ Int., 48 (2008), 1670.

21) M. B. Mourao and C. Takano: Miner. Process. Extr. Metall. Rev., 24 (2003), 183

22) Y. K. Rao: Metall. Trans., 2 (1971), 1439.

23) N. S. Srinivasan and A. K. Lahiri: Metall. Trans., 8B (1977), 175.

24) M. C. Abraham and A. Ghosh: Ironmaking Steelmaking, 6 (1979), 14.

25) R. J. Fruehan: Metall. Trans, 8B (1977), 270.

26) A. K. Viswas: Principles of Blast Furnace Ironmaking, SBA Pub., Calcutta, India, (1981), 37.

27) K. L. Trushenski, K. Li and W. O. Philbrook: Metall. Trans., 5 (1974), 1149.

28) Q. T. Tsay, W. H. Ray and J. Szekeley: AIChE J., 22 (1976), 1064.

29) T. Murayama, Y. Ono and Y. Kawai: Trans. Iron Steel Inst. Jpn., 18 (1978), 579.

30) S. Paul and S. Mukherjee: Ironmaking Steelmaking, 19 (1992), 190.

31) C. E. Seaton, J. S. Foster and J. Velasco: Trans. Iron Steel Inst. Jpn., 23 (1983), 490.

32) M. C. Mantovani, C. Takano and P. M. Buchler: Ironmaking Steelmaking, 29 (2002), 257.

33) M. Iljana, O. Mattila, T. Alatarvas, J. Kurikkala, T. Paananen and T. Fabritius: ISIJ Int., 53 (2013), 419.

34) T. Sharma, R. C. Gupta and B. Prakash: ISIJ Int., 32 (1992), 812.

35) K. Grebe, H. De Haas and H. Keddeinis: Stahl Eisen, 93 (1973), 472.

36) S. Halder and R. J. Fruehan: Metall. Mater. Trans. B, 39B (2008), 796. 